An 81-year-old man from a family with a history of oculopharyngeal muscular dystrophy (OPMD) involving 6 members over 4 generations is described. The patient first noted drooping of his eyelids at the age of 65 . Dysphagia and dysarthria occurred soon thereafter. At age 78, impairment of gait developed and progressive wasting occurred in the limbs with an initial distal distribution. Electromyography of several limb muscles displayed a mixed myopathic and neurogenic pattern with giant potentials. Examination at autopsy revealed slight loss of neurons in the anterior horns of the spinal cord, with scanty ghost cells, neuronophagia, and central chromatolysis. By light microscopy the limb muscles showed moderate small-group atrophy with severe myopathy and target fibers. The viscerocranial muscles, including the ocular, vocal, and tongue muscles, demonstrated only myopathic change with the typical features of progressive muscular dystrophy. Advanced replacement by fibrous connective tissue and fat had occurred in both the viscerocranial and the lower limb muscles. The significance of neurogenic involvement in OPMD is discussed.

\title{
AN AUTOPSY STUDY OF A FAMILIAL OCULOPHARYNGEAL MUSCULAR DYSTROPHY (OPMD) WITH DISTAL SPREAD AND NEUROGENIC INVOLVEMENT
}

HORST P. SCHMITT, MD, and K.-H. KRAUSE, MD

Since the first description of a slowly progressive familial ptosis combined with dysphagia by Taylor, ${ }^{48}$ oculopharyngeal muscular dystrophy $(\mathrm{OPMD})^{49}$ has been established within the heterogeneous group of ocular myopathies with and without generalized muscular dystrophy, as a syndrome occurring after middle age. Numerous cases have been recorded in the literature. ${ }^{1,3,4-7,18-}$ $21,25-27,39-42,45,47$

While impairment of the levator palpebrae superioris muscle, resulting in ptosis, and impairment of the pharyngeal muscles, causing dysphagia, are essential criteria in the diagnosis of OPMD, the pattern of distribution of these disorders varies with respect to the involvement of other viscerocranial muscles as well as of the trunk and limb muscles. Involvement of the tongue, the ex-

From the Institute of Neuropathology (Dr. Schmitt) and the Clinic of Neurology (Dr. Krause), University of Heidelberg, Heidelberg. West Germany

Address reprint requests to Dr. Schmitt at the Institute of Neuropathology University of Heidelberg, Im Neuenheimer Feld 220, 6900 Heidelberg 1, West Germany.

Received for publication June 6, 1980; revised manuscript accepted for publication August 13, 1980

$0148-639 \times / 0404 / 0296 \$ 01.25 / 0$

1981 John Wiley \& Sons, Inc. traocular muscles other than the levator palpebrae, and the facial and masticatory muscles is inconstant. The intrinsic laryngeal muscles are only infrequently affected. ${ }^{14,16,26,29,31,32}$

Association of other disorders such as inner ear deafness, ${ }^{16,18}$ endocrine abnormalities, ${ }^{25,29}$ and cardiac $^{16}$ and smooth-muscle ${ }^{27}$ involvement have occasionally been stressed in this disorder, which is predominantly autosomal-dominant ${ }^{4,7}$ and only rarely recessive. ${ }^{14}$ Sporadic cases may also occur. ${ }^{16,30}$

It has been shown by many authors ${ }^{1,4,6,7,14}$, 16,19-21,26,29,31,33-35,37,39,40,42,45,47,49 that the dystrophic process in OPMD may spread to the trunk and the limbs with a distal ${ }^{16,29,33,42}$ or proximal ${ }^{1,19,21,26,37}$ distribution. In the majority of cases, electromyography (EMG) and/or muscle biopsy have shown myopathic changes in both the oculopharyngeal and other involved muscles. ${ }^{7,16,26,27,29,32,37,40,42,49}$

Although the extraocular and pharyngeal muscles have always been reported to show only myopathic changes, compatible with muscular dystrophy, EMG, biopsy, and autopsy finding occasionally have revealed neurogenic involvement in the limb muscles. ${ }^{4,24,33,35}$

Barbeau ${ }^{4}$ has concluded from personal observations of reduced nerve conduction velocities and giant potentials in the EMG in several of his pa- 
tients that involvement of the central nervous system (CNS) in OPMD with distal spread cannot be ruled out.

In the few autopsy cases of OPMD which have been reported, ${ }^{30,39,40,45}$ only primary myopathic change has been demonstrated in both ocular and limb muscles.

The present report of OPMD, including complete autopsy results, details an unusual distribution and spread of the disease with simultaneous myopathic and neurogenic involvement of the limbs and myopathic involvement of the intrinsic laryngeal muscles.

\section{CASE REPORT}

The patient was 81 years old when he died of acute pulmonary embolism due to chronic thrombosis of the pelvic, thigh, and calf veins. He belonged to a family living in the Heidelberg area, in which 6 relatives over a period of 4 generations had been affected by typical OPMD. The pedigree has recently been presented in detail together with the pedigrees of 3 other affected families from the same area. ${ }^{19}$ The patient belonged to the second generation, and he had one brother suffering from the same disorder. The patient's family history and the clinical data have also been extensively delineated. ${ }^{24}$

At the age of 65 , he noticed slowly progressing drooping of his eyelids, soon followed by difficulties in swallowing and changes in phonation. By the age of 75 , ptosis had become so severe that correction by special glasses ("lunettes à béquilles"4) was necessary. He could only swallow liquids and soft food. Pharyngeal mucous congestion had become very troublesome. At 78, increasing weakness and wasting occurred predominantly in his lower limbs, and subsequently his arms became involved less severely in a pronounced distal distribution. Although his eye movements had been severely restricted, he had never been aware of diplopia. He had no sensory deficits.

About 3 weeks before death, he was admitted to the hospital for treatment of chronic venous thrombosis. Laboratory investigations revealed serum enzymes within the normal range (in units/ liter: creatine kinase [CK] 27, lactic dehydrogenase [LDH] 150, aspartate aminotransferase [SGOT] 6, alanine aminotransferase [SGPT] 13). The total plasma protein content was $6.6 \mathrm{~g} / 100 \mathrm{ml}$; bilirubin was $0.4 \mathrm{mg} / 100 \mathrm{ml}$; and serum $\mathrm{Na}, \mathrm{K}, \mathrm{Ca}$, inorganic $\mathbf{P}$, uric acid, urea, creatine, creatinine, glucose, cholesterol, and triglycerides were normal as was the peripheral blood count. The blood iron content was lowered to $49 \mu \mathrm{g} / 100 \mathrm{ml}$. Antinuclear factor was absent.

Neurological examination revealed severe ptosis, marked paresis of the soft palate, dysarthria, and severe difficulties in swallowing. Eye movements were severely limited in all directions. The patient could not sit from a reclining position and could not stand or walk without help. There was generalized muscular wasting, most marked in the distal parts of the limbs. Tendon reflexes could not be elicited. He had no pathologic reflexes. EMG of several limb muscles (biceps brachii, brachioradialis, opponens pollicis, first dorsal interosseus on both sides, quadriceps femoris, anterior tibial, and extensor digitorum brevis) showed a myopathic pattern with intermingled giant potentials and fasciculations suggesting superimposed denervation (for details see reference 24, Fig. 2). Sensory and motor conduction velocities were normal. The edrophonium test was negative.

\section{NEUROPATHOLOGICAL INVESTIGATIONS (A-NO. 981/79)}

The brain weighed $1,350 \mathrm{~g}$ after fixation in formalin. On gross inspection it displayed moderate atrophy which was pronounced in the frontocentral region. There was mild communicating hydrocephalus, probably "ex vacuo." The arteries in the circle of Willis showed dilatation and moderate focal atherosclerosis without significant stenoses.

The skeletal muscles of the lower limbs, including the pelvic girdle, were significantly wasted and yellow in color. The muscles of the buttocks and calves appeared to have little residual muscle tissue macroscopically. There was no conspicuous difference in the degree of involvement between the distal and proximal muscle groups of the legs. The muscles of the limb girdle, the arms, and the neck were in much better condition, although their pale greyish-brown color and their wasted appearance indicated that they were also affected.

The tongue appeared to consist only of fat tissue as did the levator palpebrae superioris muscle. The extraocular muscles appeared grey and pale bilaterally, as did the intrinsic laryngeal muscles, particularly of the vocal cords. The wall of the pharynx was remarkably thin without grossly demonstrable muscle tissue.

\section{MICROSCOPIC EXAMINATION}

Specimens of 15 different muscles were obtained at autopsy 20 hours after death. These included ocular muscles (levator palpebrae superioris and 
rectus medialis and lateralis from both sides), the right deltoid, rectus femoris, tibialis anterior, biceps brachii, left sternocleidomastoid, gastrocnemius, diaphragm, tongue, laryngeal, and pharyngeal muscles. They were fixed in $10 \%$ formalin, embedded in paraffin, and stained with hematoxylin and eosin ( $\mathrm{H} \& \mathrm{E})$, Sudan Black B, Masson-Goldner trichrome, and the Bodian method for axons. In addition, samples from the deep peroneal nerves, the sciatic nerve of one side, and the sural and frontal nerves from the left were treated in the same way. Numerous histological samples were prepared from the brain and the spinal cord. Paraffin sections were stained according to the Klüver-Barrera, Bodian, Nissl, and Masson-Goldner methods, and with phosphotungstic acid-hematoxylin (PTAH), Oil Red O, and Sudan Black B.

Microscopic examination revealed an advanced liposclerotic change in all ocular muscles (Fig. la-g) and viscerocranial muscles (Fig. 2a-c) examined with sometimes almost total replacement of muscle fibers by fatty and fibrous connective tissue (Figs. $1 \mathrm{~b}, 2 \mathrm{~b}$ and $\mathrm{c}$ ). The residual muscle fibers displayed significant signs of myopathic change (see below), with abundant sarcoplasmic masses and occasional segmental hyaline degeneration occurring in the ocular muscles (Fig. 1c,e,f). The myopathic nature of the changes was supported by the finding of well-preserved intramuscular nerve twigs in both the myelin and the axon preparations (Fig. 1d), which were often surrounded by fat and scanty remaining muscle fibers. The rectus medialis and lateralis muscles showed variable liposclerotic change and severe myopathy (Fig. 1a). Several motor end-plates were well preserved (Fig. 1g). Others, which had belonged to muscle fibers that had been replaced by fatty connective tissue, were poorly preserved. The related terminal axons sometimes showed spherical and cylindrical enlargements.

Examination of all motor nuclei in the lower brain stem revealed a normal amount of motor neurons without atrophy, chromatolysis, or other degenerative changes. Segments of the cranial nerves leaving the brain stem were intact. No significant changes were found in the upper motor neurons of the precentral region (area $4 \gamma$ ) or in the corticofugal tracts, either in the brain stem or at the spinal level.

The muscles of the upper and lower limbs (Fig. 3) generally showed the same microscopic features as the viscerocranial muscles. As expected from the macroscopic examination, the muscles of the lower limbs and some muscles of the arms displayed advanced liposclerotic change. The latter was only moderate in the limb girdle and neck, although pathologic change of the muscle fibers was significant. The microscopic picture was dominated by myopathic features such as rounding of fibers on cross section; varying fiber size; central nuclei with the formation of chains in longitudinal sections; fiber splitting; segmental hyaline, granular, and vacuolar degeneration (Fig. 3); increased sarcolemmal nuclei; scanty phagocytosis and regeneration phenomena; and single basophilic degenerating fibers, according to the appearance of advanced "ragged-red fibers" in $\mathrm{H} \& \mathrm{E}$.

However, another morphological component was clearly superimposed on the myopathic picture-a small-group atrophy, which was distinct in several muscles such as the biceps brachii (Fig. 3f), the rectus femoris (Fig. 3a and b), and the sternocleidomastoid. Small groups of atrophic muscle fibers, often elongated and angular on cross section, and single fibers of the same kind were scattered among the otherwise myopathically changed muscle fibers. Target fibers were repeatedly observed in different muscles (Fig. $3 \mathrm{~b}$ and c).

Examination of the spinal cord (Fig. 4) and the peripheral nerves on numerous sections from different levels of the spinal cord displayed infrequent focal abnormalities of the anterior horn neurons at the cervical and lumbosacral level consisting of ghost cells (Fig. $4 \mathrm{f}$ and $\mathrm{g}$ ) and central chromatolysis (Fig. 4a, inset in $\mathrm{f}$ and g). Occasional foci of neuronophagia were found, indicating the acute loss of some motor neurons (Fig. 4e). In addition, scanty axon spheroids (Fig. 4b) could be demonstrated in the anterior horns with Bodian impregnation. One motor neuron of the cervical enlargement showed a vacuole-like hyaline cytoplasmic inclusion (Fig. 4d), while another exhibited changes reminiscent of granulovacuolar degeneration (Fig. 4c).

Surprisingly, single neurons of the nucleus proprius of the posterior column also exhibited early central chromatolysis (Fig. 4i). While most of the long spinal tracts were normal, a marked "loosening" of the posterior columns suggesting a loss of myelinated fibers, but without signs of acute fiber degeneration, was found (Fig. 4h). One small glial star was observed in addition. There were no axon spheroids. The described findings were most prominent at the cervical level (Fig. 4h top). There was no atrophy of the dorsal columns and no meningeal thickening. Fibrillary gliosis was moderate. 

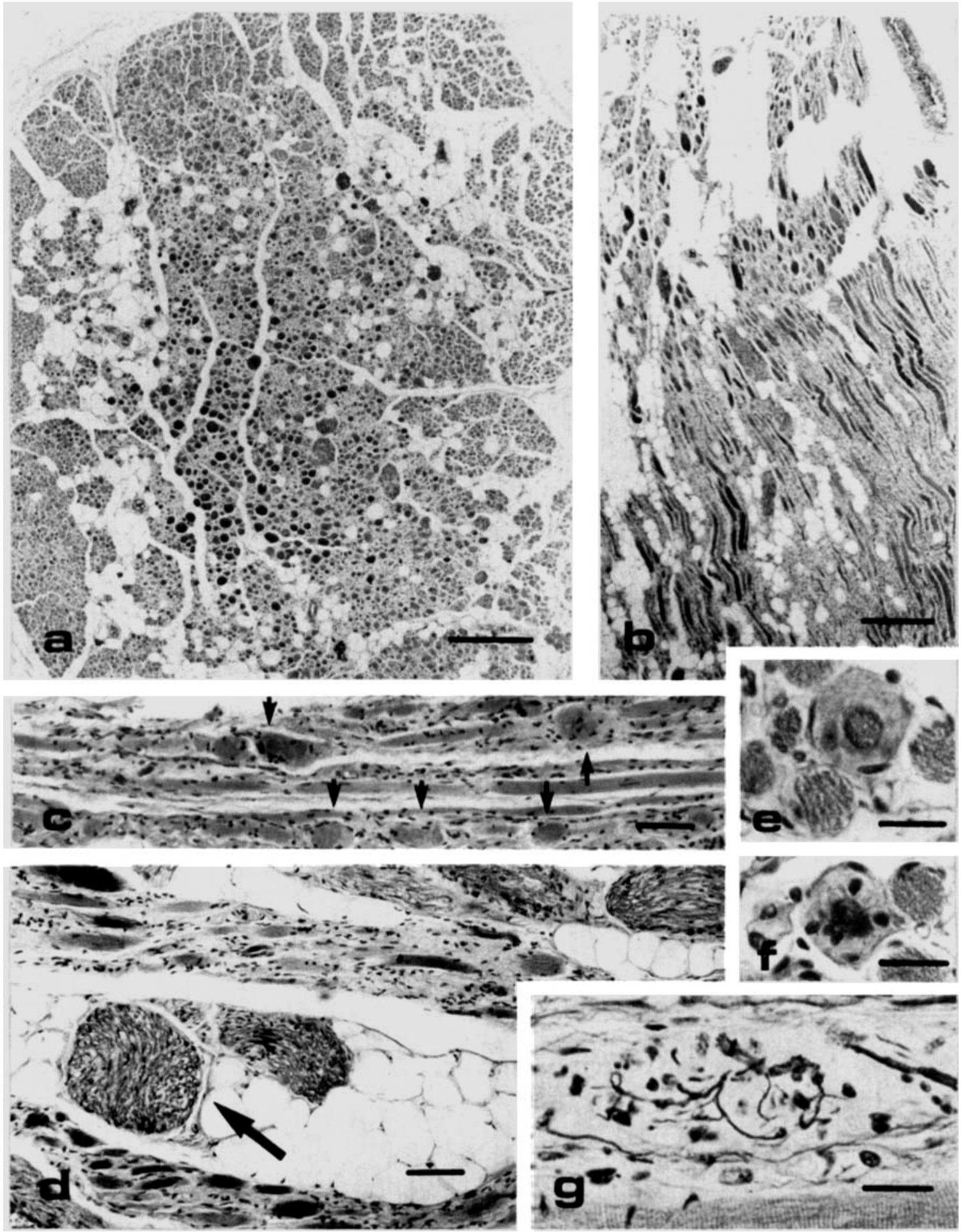

Figure 1. Histological changes of the ocular muscles in the patient with oculopharyngeal muscular dystrophy: (a) liposclerotic change and severe myopathy in the rectus medialis (Masson-Goldner); (b) replacement of muscle fibers by fatty and fibrous connective tissue in the levator palpebrae superioris (Masson-Goldner); (c) segmental hyaline degeneration (arrow) (hematoxylin and eosin); (d) well-preserved intramuscular nerve twigs (arrow) (Masson-Goldner); (e,f) sarcoplasmic masses (Masson-Goldner): ( $g$ ) intact motor end-plates (Bodian) (c-g muscle: levator palpebrae superioris). Bars in $a, b=500 \mu \mathrm{m} ; c, d=50 \mu \mathrm{m} ; e, t, g=30 \mu \mathrm{m}$ 

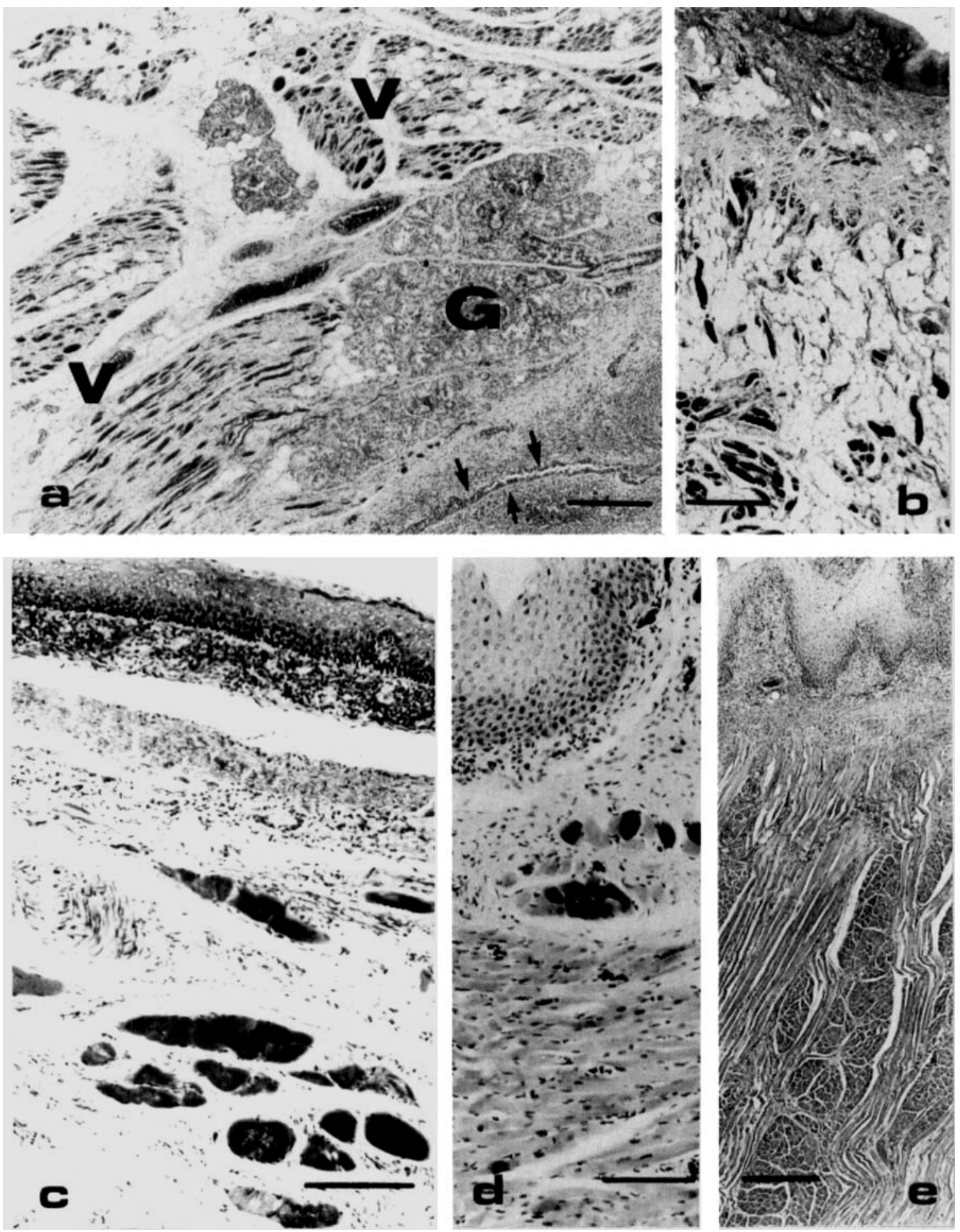

Figure 2. Histological changes of the viscerocranial muscles in the patient with oculopharyngeal muscular dystrophy: (a) vocal cord $(V=$ vocal and internal thyroarytenoid muscle, $G=$ submucous glands, arrows indicate part of the glottic slit) with numerous fat vacuoles replacing the muscle fibers in $V ;(b)$ tongue and (c) pharynx both showing few residual degenerated muscle fibers; (d) normal pharynx; (e) normal tongue for comparison. Masson-Goldner in all muscles. Bars in a,b,e $=500 \mu m ; c, d=100 \mu m$ 

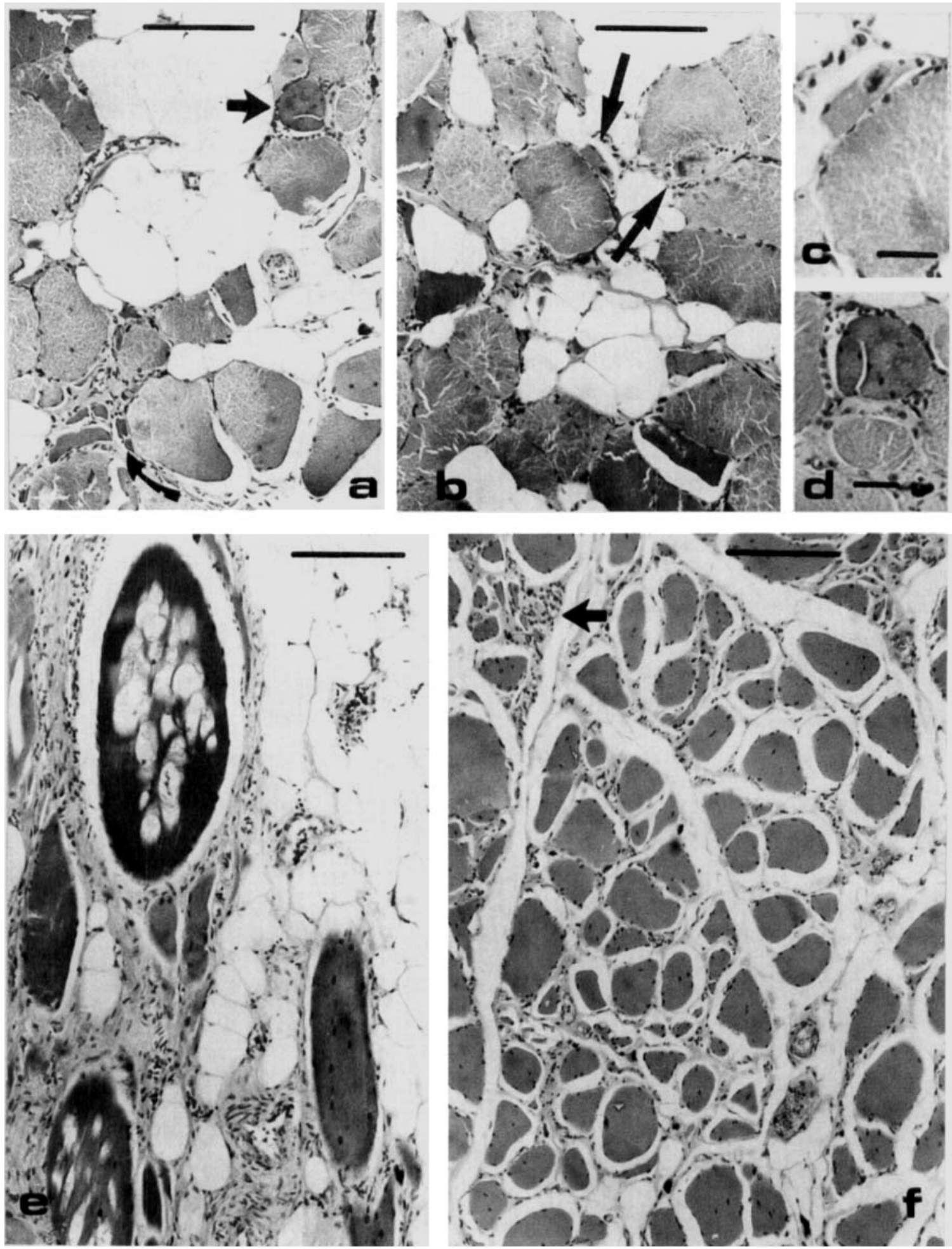

Figure 3. Histological changes of the limb muscles in the patient with oculopharyngeal muscular dystrophy: $(a, b)$ rectus femoris showing liposclerotic change and myopathic features, including central nuclei, fiber splitting, and sarcoplasmic mass (straight arrow in a) with a small group of atrophic fibers (bent arrow in a) and 2 target fibers (straight arrows in b) (Masson-Goldner); (c,d) high-power magnifications of the target fiber, fiber splitting, and sarcoplasmic mass shown in a and $b$; (e) vacuolar degeneration in the rectus femoris (hematoxylin and eosin); ( $f$ ) biceps brachii showing one small group of atrophic fibers (arrow) with others appearing elsewhere in the field (hematoxylin and eosin). Bars in $a, b, e, f=100 \mu \mathrm{m} ; c, d=25 \mu \mathrm{m}$. 

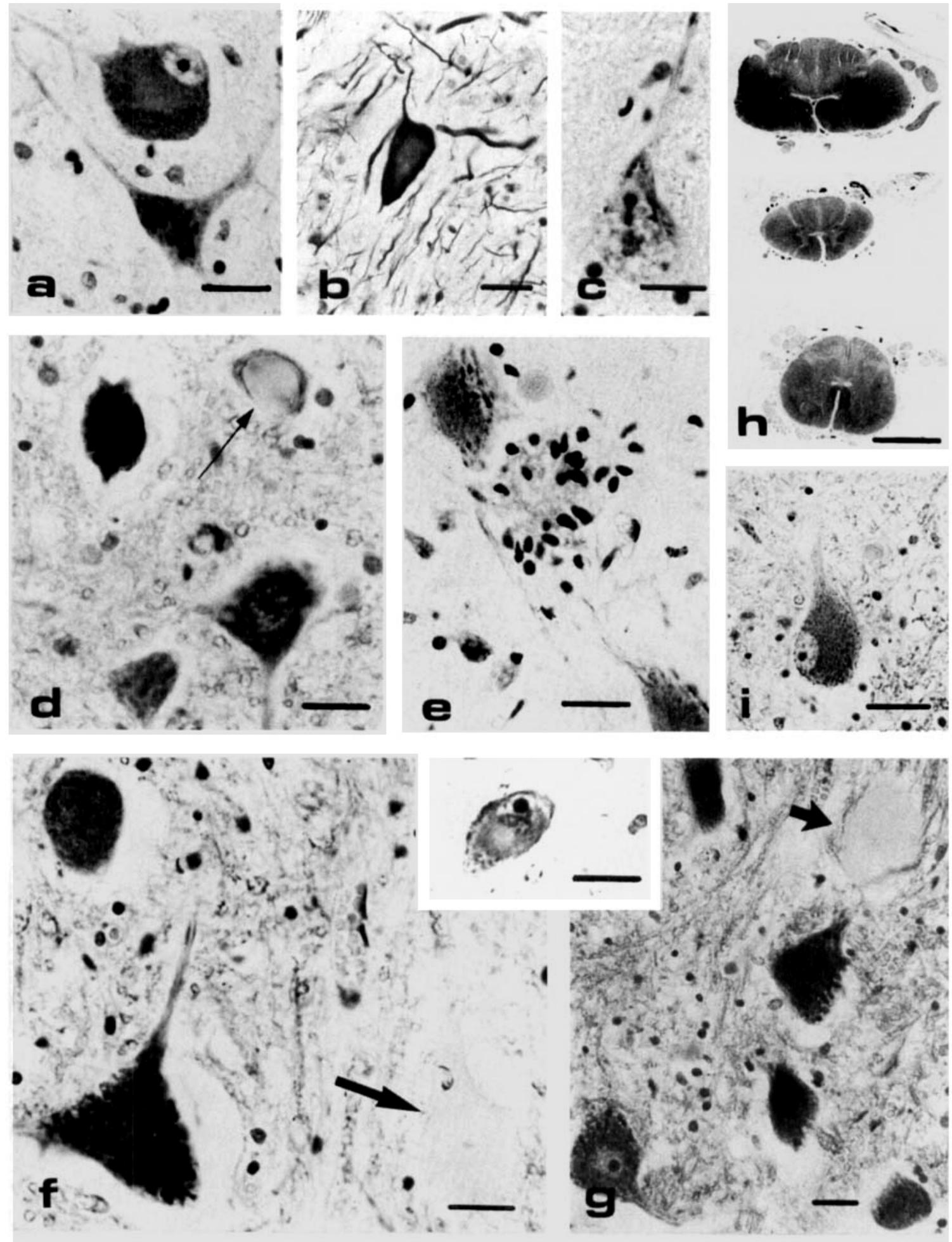

Figure 4. Histological changes of the spinal cord in the patient with oculopharyngeal muscular dystrophy: (a) early central chromatolysis; (b) axon "spheroid;" (c) granulovacuolar-like change of a motor neuron; (d) "hyaline" inclusion (arrow); (e) neuronophagia; (f) ghost cell (arrow); ( $g$ ) ghost cell or axon spheroid (arrow); (inset in $f$ and g) advanced central chromatolysis (a-g all obtained from the anterior horns of the cervical and lumbosacral spinal cord) (staining: Luxol-Fast-Blue-Nissl); ( $h$ ) "loosening" of the posterior column (Sudan Black B); (i) early chromatolysis of a neuron of the nucleus proprius of the posterior horn. Bar in $h=$ $5 \mathrm{~mm} ; \mathrm{a}-\mathrm{i}=30 \mu \mathrm{m}$. 
The anterior and posterior roots did not exhibit loss of myelinated fibers at the light microscopic level. There was no acute demyelination. The same was true for the peripheral nerves except that there were scanty digestion chambers in the myelin preparations of the motor nerves. Axon spheroids were not observed.

A small pea-sized neurinoma was attached to one rootlet of the cauda equina. Signs of compression or damage to adjacent rootlets were absent.

\section{Discussion}

An 81-year-old man is described, who was a member of a family in which 6 relatives over a period of 4 generations were affected by late-onset progressive ptosis, external ophthalmoplegia, and dysphagia. In addition to these symptoms of OPMD, the patient had developed progressive weakness and wasting of the limbs with clinical signs of both myopathic and neurogenic change. Suspicion of a denervation atrophy superimposed on a severe myopathy in the limbs and trunk had first been elicited by the finding of a mixed myopathic and neurogenic pattern in the EMG of different limb muscles. ${ }^{24}$ The denervation component had been indicated by giant potentials akin to those which have been reported comprehensively by Barbeau, ${ }^{4}$ who felt that an involvement of the CNS in OPMD cannot be ruled out.

The autopsy findings in the spinal cord of our case confirmed the neurogenic component, which might be assessed as a mild progressive spinal muscular atrophy, according to the changes described in the spinal cord (Fig. 4) and the mild degree of the neurogenic atrophy in the limb muscles. It was restricted to a moderate small-group atrophy and scattered single-fiber atrophy in various muscles. Although histochemical enzyme examinations were not performed, this atrophy is probably not just a nonspecific type 2 atrophy or some incidental grouping of myopathic fibers, as it may occur in the limb-girdle muscular dystrophies, ${ }^{8}$ in malnutrition, and in OPMD. ${ }^{5}$ The neurogenic nature of the grouped atrophy is supported by both the findings of motor neuron deficits in the spinal cord and the demonstration of target fibers in different limb muscles. These target fibers were both in normally sized and in atrophic fibers (Fig. 3a and b), in which they have been shown to occur to a minor extent. ${ }^{44}$

In contrast to the limb muscles, the oculopharyngeal and the other viscerocranial muscles showed pure myopathic changes consistent with the picture of progressive muscular dystrophy, as has been shown in numerous cases of external ophthalmoplegia and OPMD. ${ }^{22,23,36,46}$ The intramuscular nerve branches were well preserved. Segmental hyaline degeneration, which has been thought to be the basic process in OPMD ${ }^{39}$ was demonstrated in various ocular muscles and other somatic muscles in the present case. In the limb muscles the myopathic changes definitely dominated the neurogenic component. Myopathic involvement and liposclerotic change were severe even in those muscles in which denervation atrophy would not have been suspected from the histological picture. The extent of the dystrophic process was the same in the pelvic girdle and the lower limbs as in the oculopharyngeal muscle group. It seemed as if the process had "jumped" from the viscerocranial muscles to the legs and then slowly progressed upwards to the limb girdle and the arms. The superimposed denervation atrophy was found to be of the same minor extent in the upper and the lower limbs, making it unlikely that a different degree of denervation atrophy was the cause of the striking regional variation of the muscle change.

In our review of the literature, denervation atrophy of the limb muscles in OPMD has only been substantiated twice ${ }^{33,35}$ besides Barbeau's ${ }^{4}$ report. The autopsy case reported by Myrianthopoulos and Brown, ${ }^{35}$ however, cannot be compared with the present one without reservation, because, according to the author's description, this case (III-25) demonstrated pure spinal muscular atrophy in the limbs and pure muscular dystrophy in the oculopharyngeal muscles. The same is obviously true for a case reported by Matsunaga et al..$^{33}$ (case 1).

Combination of external ophthalmoplegia with spinal muscular atrophy has been reported by Croft et al. ${ }^{11}$ (cases 10-13). In the family of our case, no other combinations of OPMD with neurogenic impairment have been detected.

Complete autopsy examinations in OPMD by Schotland and Rowland ${ }^{45}$ (2 cases), Roberts and Bamforth $^{40}$ (case 7), Rebeiz et al. ${ }^{39}$ (1 case), and Man et al. $^{30}$ ( 1 case) have only demonstrated myopathic changes in both the limb and the viscerocranial muscles. In the present case, both muscular dystrophy and spinal muscular atrophy occurred in the limbs. From our observations at autopsy, we cannot support the conclusion of Radu et al. ${ }^{38}$ that denervation atrophy does not produce typical denervation patterns in previously dystrophic muscles. 
We do not feel that our findings support Barbeau's presumption of CNS involvement in OPMD. In our case one must consider that the predominant process was a myopathy or muscular dystrophy, while denervation atrophy was a comparatively minor feature. It is more likely that spinal muscular atrophy was fortuitously superimposed, particularly if one considers the late age at which it occurred. Slight loss of spinal motor neurons is frequently found in elderly patients. ${ }^{2}$ In addition, metabolic disturbances due to longstanding malnutrition, which may result from the basic pharyngeal disorder, may have exaggerated "age-dependent" loss of motor neurons in the present case.

In the vast majority of cases of OPMD, neurogenic impairment has not been demonstrated. In contrast to the former understanding, ${ }^{3,13,15,17,35,48}$ neurogenic impairment has also never been demonstrated in external ophthalmoplegia, except in the complicated cases cited above. .1,33,35

Rebeiz et al. $^{39}$ have provided the interesting interpretation that OPMD may not be a true progressive muscular dystrophy but just a presenile, pathologically exaggerated aging process comparable to Alzheimer's disease. However, the very early onset of OPMD in some cases ${ }^{14.26,29.32 .34 .40}$ does not seem to favor this hypothesis. In the present case a considerable dissociation between neuronal and muscular "aging" would have occurred without any comprehensive reason.

A special feature of the present case is the involvement of the intrinsic laryngeal muscles. Laryngeal involvement in other muscular diseases, except myasthenia gravis, has been reported only rarely, in such cases as congenital myopathy with arthrogryposis ${ }^{\mathbf{9 . 1 0 , 4 3}}$ and scapuloperoneal muscular atrophy. ${ }^{28,50}$

The significance of the changes in the posterior column of the spinal cord in the present case remains obscure. In rare cases of external ophthalmoplegia, Croft et al. ${ }^{11}$ (case 10) and Direkze ${ }^{12}$ described signs of posterior column change. We feel that these changes in our case are nonspecific and age-dependent.

\section{REFERENCES}

1. Aarli JA: Oculopharyngeal muscular dystrophy. Acta Neurol Scand 45:484-492, 1969

2. Adams RD: Diseases of Muscle. A Study in Pathology, 3rd Ed. Harper \& Row, Hagerstown, MD, 1975, p 217

3. Amyot R: Hereditary, familial and acquired ptosis of late onset. Can Med Assoc J 59:434-438, 1948

4. Barbeau A: The syndrome of hereditary late onset ptosis and dysphagia in French Canada. In Progressive Muskeldystrophie. Edited by Kuhn E. Springer-Verlag, Berlin, West Germany, 1966, pp 102-109

5. Bosch EP, Gowans JDC, Munsat TH: Inflammatory myopathy in oculopharyngeal dystrophy. Muscle Nerve 2:73-77, 1979

6. Bray GM, Kaarsoo M, Ross RT: Ocular myopathy with dysphagia. Neurology (Minneap) 15:678-684, 1965

7. Campanella G, Filla A, Serlenga L, Frederico A, Buscaino GA: Myopathie oculo-pharyngée. Rev Neurol (Paris) $131: 615-628,1975$

8. Coërs CH, Telerman-Toppet N: Fact and fancy in the histological diagnosis of denervation. In Peripheral Neuropathies. Developments in Neurology, I. Edited by Canal N, Pozza G. Elsevier/North Holland, Amsterdam, The Netherlands, 1978, pp 25-36

9. Cohen SR: Arytenoidectomy in children. Larymgoscope $83: 1293-1299,1973$

10. Cox DJ, Simmons FB: Midline vocal cord fixation in the newborn. A new syndrome. Arch Otolaryngol 100:219, 1974

11. Croft PB, Cutting JC, Jewesbury ECO, Blackwood W, Mair WGP: Ocular myopathy. (Progressive external ophthalmoplegia with neuropathic complications.) Acta Neurol Scand 55:169-197, 1977

12. Direkze M: Progressive external ophthalmoplegia-some clinical associations. Acta Neurol Scand 49:195-204, 1973

13. Dutil A: Note sur une forme de ptosis non-congenital et héréditaire. Prog Méd (Paris) 20:401-403, 1892

14. Fried K, Arolozorov A, Spira R: Autosomal recessive oculopharyngeal muscular dystrophy. J Med Genet 12: $416-418,1975$

15. Fuchs E: Über isolierte und doppelseitige Ptosis. Graefe's Arch Vergl Ophthalm 36:234-259, 1890

16. Goto I, Kanazawa Y, Kobayashi T, Murai Y, Kuroiwa Y: Oculopharyngeal myopathy with distal and cardiomyopathy. J Neurol Neurosurg Psychiatry 40:600-607, 1977

17. Graef von $A$ : Verhandlungen ärztlicher Gesellschaften. Klin Wochenschr 5:125-127, 1868

18. Graf K: Myopathia oculo-pharyngealis tarda hereditaria. Pract Oto-Rhino-Laryngol (Basel) 33:203-208, 1971

19. Hartmann A, Berendes K: Die oculopharyngeale Muskeldystrophie. Nervenarzt 50:788-793, 1979

20. Hayes R, London W, Seidman J, Embree L: Oculopharyngeal muscular dystrophy. $N$ Engl J Med 268:163, 1963

21. Julien J, Vital C, Vallat JM, LeBlanc M: Oculopharyngeal muscular dystrophy. J Neurol Sci 21:165-169, 1974

22. Kearns TP, Sayre GP: Renitis pigmentalis, external ophthalmoplegia and complete heart block: unusual syndrome with histologic study in one of two cases. Arch Ophthalmol 60:280-289, 1958

23. Kiloh LG, Nevin S: Progressive dystrophy of the external ocular musles (ocular myopathy). Brain 74:115-143, 1951

24. Krause K-H, Schmitt HP: Okulopharyngeale Muskeldystrophie mit neurogener Muskelatrophie. Syndrom oder zufälliges Żusammentreffen? Nervenarzt 52:79-84, 1981

25. Lakin M, Locke S: Progressive ocular myopathy with ovarian insufficiency and diabetes mellitus. Diabetes 10:228231,1961

26. Lees F, Liversedge LA: Descending ocular myopathy. Brain 85:701-710, 1962

27. Lewis J: Late-onset muscle dystrophy: oculopharyngoesophageal variety. Can Med Dis J 25:146-147, 1966

28. Liversedge LA, Campbell MJ: Scapuloperoneal atrophy. In 
Disorders of Voluntary Muscle. Edited by Walton JN. Churchill Livingstone, London, England, 1974, pp 782-783

29. Lundberg PO: Ocular myopathy with hypogonadism. Acta Neurol Scand 38:142-155, 1962

30. Man HX, Mihol J, Guillard A, Boudin G: Etude anatomoclinique d'une myopathie oculopharyngie. Bull Soc Ophthalmol Fr 76:23-30, 1976

31. Maningand G, Lucso $M$, Deparis $M$ : Les myopathies oculaires. A propos d'une observation familiale de dystrophie musculaire oculo-pharyngée et squelettique à début tardif. Sem Hop Paris 45:2803-2808, 1969

32. Mater JM, Stoebner P, Stephan F, Isch F: Myopathie oculaire compliqué tardivement d'une atteinte des muscles de la déglutition, de la phonation et de la racine des quatre membres. Rev Otoneuroophtalmol 41:315-323, 1969

33. Matsunaga $M$, Inokuchi $T$, Okuishi A, Kuroiwa $Y$ : Oculopharyngeal involvement in familial neurogenic muscular atrophy. J Neurol Neurosurg Psychiatry 36:104-111, 1973

34. Murphy SF, Drachman DB: The oculopharyngeal syndrome. JAMA 203:99-104, 1968

35. Myrianthopoulos NC, Brown JA: A genetic study of progressive spinal muscular atrophy. Am J Hum Genet 6: $387-441,1954$

36. Nicolaissen B, Brodal A: Chronic external ophthalmoplegia (report of a case with histopathologic examination of external eye muscle and skeletal muscle). Arch Ophthalmol $61: 202-210,1959$

37. Peterman AF, Lillington GA, Jamples RW: Progressive muscular dystrophy with ptosis and dysphagia. Arch Neurol 10:38-41, 1964

38. Radu H, Ionasescu V, Radu A: Duchenne muscular dystrophy and poliomyelitis. A study of dystrophic-denervated muscle. Z Neurol 209:225-236, 1975

39. Rebeiz JJ, Caulfield JB, Adams RD: Oculopharyngeal dystrophy-a presenescent myopathy: a clinico-pathologic study. In Progress in Neuro-ophthalmology, Vol. II. Edited by
Brunette JR, Barbeau A. Excerpta Medica, Amsterdam, The Netherlands, 1969, pp 12-31

40. Roberts AH, Bamforth J: The pharynx and esophagus in ocular muscular dystrophy. Neurology (Minneap) 18:645652,1968

41. Saucier J: The clinical significance of ptosis with special reference to ptosis of late onset.J Nero Ment Dis 119:148-158, 1954

42. Satoyoshi E, Murakami K, Kowa $H$, Kinoshita M, Torii J; Distal involvement of the extremities in ocular myopathy. Am J Ophthalmol 59:668-673, 1965

43. Schmitt HP: Involvement of the larynx in a congenital "myopathy," unilateral aplasia of the arytenoid, micrognathia and malformation of the brain-a new syndrome? Virchows Arch Pathol Anat 381:85-96, 1978

44. Schmitt HP: Quantitative analysis of the size distribution of target and targetoid fibers employing the method of Daeves and Beckel for mixed distributions. Acta Neuropathol (Berl) 45:215-220, 1979

45. Schotland DL, Rowland LP: Muscular dystrophy. Features of ocular myopathy, distal myopathy, and myotonic dystrophy. Arch Neurol 10:433-445, 1964

46. Schwarz GA, Liu GN: Chronic progressive external ophthalmoplegia, clinical and neuropathologic report (ocular myopathy). Arch Neurol Psychiatry 71:31-53, 1954

47. Szobar A: Data on the oculopharyngeal syndrome. Eur Neurol 9:242-259, 1973

48. Taylor EW: Progressive vagus-glossopharyngeal paralysis with ptosis. A contribution to the group of family diseases. $J$ Nerv Ment Dis 42:129-139, 1915

49. Victor M, Hayes R, Adams RD: Oculopharyngeal muscular dystrophy. A familial disease of late life characterized by dysphagia and progressive ptosis of the eyelids. $N$ Engl J Med 267:1267-1272, 1962

50. Zellweger H, McCormick WF: Scapuloperoneal dystrophy and scapuloperoneal atrophy. Helv Paediatr Acta 23:643649,1968 